\title{
Looking for opinion leaders: traditional vs. modern measures in traditional societies
}

\author{
Gabriel Weimann, Deon Harold Tustin, Daan van Vuuren and J. P.
} R. Joubert

\begin{abstract}
Since the introduction of the opinion leadership conceptualization, both practitioners and academics have been keenly interested in its applicability in modern society. Numerous studies have been conducted to identify potential opinion leaders, learn of the characteristics distinguishing them from their 'followers,' and understand how they exert their personal influence to change opinions and behaviors of the masses. Despite the growing research on opinion leadership, the identification of appropriate opinion leaders for practical purposes continues to be a challenge. Several methods were used to identify opinion leaders. The existence of numerous methods and their use in various societies, social settings and cultures and the variance across domains of opinion leadership raises questions on the applicability and validity of the modern, advanced measures when applied to other social settings. The present study is in fact a first attempt to apply the modern personality strength (PS) scale to a traditional community. The PS scale was found to be an efficient, valid, and useful instrument to identify opinion leaders in numerous studies. However, it was always used, tested, and validated in Western societies (e.g., Germany, USA, and Israel). When we applied the method in the Skukuza community, a small village in South Africa, the findings revealed the inapplicability of the scale in a traditional community. Several factors are suggested to explain the futility of the PS scale in a traditional society.

'The masses do not now take their opinions from dignitaries in Church or State, from ostensible leaders, or from books. Their thinking is done for them by men much like themselves, addressing or speaking in their name, on the spur of the moment...'

(John Stuart Mill, On Liberty)

Decades of social science research have demonstrated that there is a group of people in any community to whom others look to help them to form opinions on various issues and matters (Weimann, 1994). Whether called 'opinion leaders' or 'influentials,' these people literally lead the formation of
\end{abstract}


attitudes, public knowledge, and opinions. In the classic book, Personal Influence, opinion leadership is defined as:

... leadership at its simplest: it is casually exercised, sometimes unwitting and unbeknown, within the smallest groupings of friends, family members, and neighbors. It is not leadership on the high level of Churchill, nor of a local politico; it is the almost invisible, certainly inconspicuous form of leadership at the person-to-person level of ordinary, intimate, informal, everyday contact.

(Katz \& Lazarsfeld, 1955)

Since the introduction of the opinion leadership conceptualization, both practitioners and academics have been keenly interested in its applicability in modern society. Numerous studies have been conducted to identify potential opinion leaders, learn of the characteristics distinguishing them from their 'followers', and understand how they exert their personal influence to change opinions and behaviors of the masses. Many of these studies have validated that opinion leaders do indeed exist and influence others, in various areas, ranging from fashion and consumer decisions to politics. Such opinion leaders, also referred to as the 'influentials,' are individuals regarded as having expertise and knowledge on a particular subject. These individuals often provide information and advice to 'followers'; therefore, they are more likely to influence purchasing behavior through word-of-mouth communication.

Opinion leadership theory has many implications for advertising and marketing. First, opinion leaders can affect diffusion of innovation. Because of this, they can also spur new product interest as well as trial. In contrast to other people, they generally get more involved in a product category and will aggressively search for information on it. As a result, they will be more likely to talk about products with others and solicit others' opinions too (Solomon, 1994, p. 386). Then, product opinion leaders are more than just innovators. They are innovative and active communicators because they go one step beyond being merely early purchasers to actually communicate both positive and negative information about the product. Furthermore, opinion leaders are seen as having special advantages: First, these leaders are perceived to possess 'expert power' because they are technically competent and are convincing (Rogers, 1983). Second, product opinion leaders have knowledge power because 'they have prescreened, evaluated, and synthesized product information in an unbiased way' (Menzel, 1981). They are attributed social power due to their standing in the community (Solomon, 1994, p. 385). Third, this hands-on product experience makes opinion leaders more likely to give both positive and negative information about the product's performance-unlike paid communication which focuses exclusively on a product's positive aspects (Solomon, 1994, p. 385). Finally, they have referent power since they usually tend to be homophilous, or similar in terms of education, social status, and beliefs with their opinion-seeking counterparts (Rogers, 1983). 
Therefore, it is imperative that companies conduct research to identify opinion leaders. The knowledge gained from these studies can then be utilized to properly target information to the appropriate settings and media.

\section{THE CONCEPT OF OPINION LEADERSHIP}

\section{SOME HISTORY}

Since its discovery in the 1940s, the theory of opinion leadership, or the two-step flow model, has provided some understanding of how information and ideas are disseminated through both mass media and networks of interpersonal communication. Three major studies laid the groundwork for opinion leadership theory, including the People's Choice Study (Lazarsfeld, Berelson, \& Gaudet, 1948), the Decatur Study (Katz \& Lazarsfeld, 1955), and the Drug Study (Menzel, 1981). Each study led to a greater understanding of how opinion leaders disseminate information-from the more simplistic two-step flow of communication to the more elaborate model, the multi-step flow of communication. The two-step flow theory asserts that information from the media moves in two distinct stages - from the mass media to the opinion leaders and from the opinion leaders to their followers. The two-step idea was first introduced by Paul Lazarsfeld, Bernard Berelson, and Hazel Gaudet (1948) in The People's Choice, a study that focused on the process of decision making during a Presidential election campaign.

Despite a number of criticisms by subsequent researchers, the People's Choice study is considered one of the most prominent studies in mass communication research due to its comparison between the mass media and personal flow of information and influence (Weimann, 1994). Criticisms are directed at the oversimplification of the two-step flow of communication, thus the underestimation of the direct influence of the media (Weimann, 1994). The process of influence is said to be more complex than a single group of opinion leaders listening to the mass media, then feeding their opinions to a group of passive followers). Instead, people who influence others are themselves influenced by others in the same topic area, resulting in an exchange. Opinion leaders are, thereby, both disseminators and recipients of influence. With this in mind, a more accurate portrayal of the communication flow would be a multi-step process, rather than simply a two-step process (Weimann, 1982).

The two-step flow of communication theory has been able to remain relevant throughout the years. Several recent studies have addressed issues arising from Lazarsfeld's, Katz's, and Merton's studies from the 1940s (Lazarsfeld et al., 1948; Merton, 1949; Katz \& Lazarsfeld, 1955). For example, Weimann (1991; 1994) conducted a re-examination of the opinion leader conceptualization in modern studies, attempting to spark a new interest in the old theory and modify the definition and measurement of opinion leaders. 
Weimann and Brosius (1994; Brosius \& Weimann, 1996) examined the process of agenda setting as a two-step flow of communication, highlighting the role of opinion leaders in mediating between media agendas and public agendas.

\section{WHO ARE THE OPINION LEADERS?}

The early studies on personal influence and opinion leadership resulted in several attributes related to opinion leaders. Let us briefly review the main ones:

- Opinion leaders are found at every social level, and in most areas of decision making they influence people from the same social level.

- Opinion leaders are found in both sexes, all professions, all social classes, and all age groups.

- Opinion leaders tend to be more involved in various social activities and social organizations and occupy central positions in their personal networks.

- Opinion leaders are considered experts in their field, but this is an informal recognition by close friends, relatives, co-workers, colleagues, and acquaintances.

- Opinion leaders are more exposed to the mass media than nonleaders.

- Opinion leaders are more interested, involved, and updated in the field in which they are influential.

- Opinion leaders tend to be monomorphous: they are usually experts in one area but rarely in various areas (i.e., polymorphous).

- Opinion leaders manifest a specific communication behavior: They are more involved in formal and informal personal communication than nonleaders.

- Opinion leaders are usually well aware that they are sources of information and influence for others.

In his review of the opinion leadership concept after the early studies, Elihu Katz (1957) suggested three criteria that distinguish the leaders from nonleaders: (1) Who one is: the personification of certain values by the opinion leader's figure; (2) What one knows: the competence or knowledge related to the leaders; and (3) Whom one knows: the strategic location in the social network. A more debatable characterization relied on the use of the mass media, or the so-called two-step flow model.

There has been lengthy debate as to the existence of 'generalized opinion leaders' (somebody whose recommendations are sought for more than one area or domain). Although rare, generalized opinion leaders are thought to exist. Charles King and John Summers (1970) analyzed the overlap of opinion leadership across six broad product categories. They reported substantial 
overlap across categories, particularly across those product categories of similar interest. The current presumption, however, is that very few people are capable of being expert in a number of fields.

\section{MEASURING OPINION LEADERSHIP}

Despite the growing research on opinion leadership, the identification of appropriate opinion leaders for practical purposes continues to be a challenge. Several methods were used to identify opinion leaders:

i. Positional: In this approach, persons in elected or appointed positions in the community are assumed to be opinion leaders. Thus, the school superintendent, city council persons, and the mayor would be assumed to be opinion leaders on school-related issues. This approach is inexpensive-one could learn with a telephone call to the local courthouse who occupies elected and appointed positions. But the approach can be highly inaccurate because it assumes opinion leadership based upon position, rather than respect.

2. Reputational: The reputation approach relies upon the nominations of selected individuals on, for example, 'the ten most influential persons in this community regarding a certain issue'. Using the reputational approach generally improves the accuracy of identifying opinion leaders because one is getting information from more than one source about the influence of others in the community.

3. Self-designating: Here, individuals are asked to identify themselves as being influentials in certain issues. The approach has the advantage of getting input on influence from community members, and therefore is more accurate than the positional approach. A potential pitfall of the self-designating approach is that persons might over- or under-estimate their influence on others. A selfdesignating questionnaire was developed by King and Summers (1970). The original 7-item scale gauged the direction of influence between friends relative to a specific product. Realistically considered, however, this methodology sacrifices a moderate degree on accuracy for the sake of economics and expediency: 'The self-designating method is not as reliable as a more systematic analysis (in which individual claims of influence can be verified by asking others whether the person is really influential), but it does have the advantage of being easy to apply to a large group of potential opinion leaders' (Solomon, 1999, p. 359).

4. Sociometric: Sociometric methods trace communication patterns among members of a group, which allows for the systematic mapping of member interactions. Data is typically obtained by interviewing participants and asking them to whom they go for advice and guidance. This method is 
more precise than the self-designating method, but is more expensive and difficult to administer. Sociometry works best in a closed, self-contained social setting, such as hospitals, prisons, or army bases. This mapping of contacts serves to locate persons who are at the center of communications about the issue area. Sociometric maps can help identify 'natural' boundaries among cliques of opinion leaders and the interstitial persons who link leadership cliques (Weimann, 1982).

5. Observation: Another method of data collection on opinion leadership and advice-giving is by observing social action within the community. Observation, because of costs related to its application and the length of time required, is the most expensive of the techniques described here, but it is often considered the most accurate.

6. Key informant approach: It involves first identifying a limited number of people assumed to be knowledgeable regarding the patterns of influence within a group, and then asking them to identify influentials in that group. Although key informants are selected subjectively as persons likely to have the ability to identify opinion leaders, this method is employed as it usually produces savings in terms of costs and time when compared to other methods. However, it should be noted that there are limits to applicability of this methodology in sample designs, in which only a portion of an audience is interviewed.

\section{The Personality Strength Scale:AModern Measure}

It was the German news magazine, Der Spiegel, that initiated the development of the new measure. Interested in what they referred to as 'the active consumers who set standards in their community', managers of Der Spiegel challenged the Allensbach Institut with the task of developing an instrument that would identify the influentials among the readers. The researchers, headed by Noelle-Neumann, suggested a measure to be called the 'Personality Strength Scale' (Personlichkeitsstdrke) or the PS scale, emerging from testing numerous questionnaire items related to self-perceived levels of personal influence (Noelle-Neumann, 1983, 1985). These early scales were tested and refined after years of pretests with a variety of samples. The final scale included 10 items that were later weighted according to their part-whole correlations with the total scale. The scores on the final scale range from 75 to 149, making it possible to place individuals on a continuous scale or group them according to levels of influence. The 10 items included in the PS scale and the respective weights are presented in Table 1.

The procedure used by the Allensbach Institute to validate the scale involved a somewhat questionable procedure based on the comparison of the scale ratings with the interviewers' impression. These two measures were 


\section{TABLE I The personality strength (PS) scale: Items and weighting}

\begin{tabular}{llrr} 
& & \multicolumn{2}{c}{ Weight } \\
\cline { 3 - 4 } Item & Yes & No \\
\cline { 3 - 4 } 1 & I usually rely on being successful in everything I do & 13 & 7 \\
2 & I am rarely unsure about how I should behave & 14 & 7 \\
3 & I like to assume responsibility & 15 & 7 \\
4 & I like to take the lead when a group does things together & 17 & 8 \\
5 & I enjoy convincing others of my opinions & 15 & 7 \\
6 & I often notice that I serve as a role model for others & 16 & 8 \\
7 & I am good at getting what I want & 14 & 7 \\
8 & I am often a step ahead of others & 18 & 9 \\
9 & I have many things others envy me for & 15 & 9 \\
10 & I often give others advice and suggestions & 12 & 6 \\
& Maximum score & I449 & \\
& Minimum score & & 75
\end{tabular}

found to be highly correlated but this test is weakened by the possibility that the interviewers were influenced by the respondents' self-assessment. The need to validate the scale by an 'external' criterion led to its testing in Israel and the USA (Weimann, 1991). The scale was administered to two Israeli samples. The first $(n-650)$ was randomly drawn from the adult Jewish population of Israel. It was used to examine the applicability of the PS scale to another society and to relate the scale's ratings to other measures (sociodemographic characteristics, measures of media use and interests, patterns of sociability, and others). The comparison of the German sample with the Israeli sample in terms of the PS scale revealed similar patterns: A factor analysis of the responses to the 34-item questionnaire (using a principal components solution with Varimax rotation) revealed that, in both samples, the same 10 items emerged as strongly loaded on one factor, accounting for 40-42 percent of the variance.

A split-half reliability test for both samples yielded satisfactory coefficients of .78 and .76 for the German and Israeli data, respectively. When the 10-item scale itself is factor analyzed, two distinct factors emerge: a principle one accounting for 75 percent of the variance (72 percent in the Israeli sample) that includes seven items and a second factor that includes three items. The first factor seems to measure internal sources of influenceability (e.g., items like 'I like to assume responsibility,' or 'I usually count on being successful in everything I do'), whereas the second describes 'external' origins, derived from comparison with other people (e.g., 'I am often a step ahead of others'). 
Although the PS scale yields similar results in two different societies, this is not an indicator of its validity. Is it really a measure of influenceability? To validate the scale a second sample was studied. This was an Israeli kibbutz community $(n-270)$ that, in a former study, underwent a sociometric mapping of its personal communication network and the flow of information and influence in this network (for a detailed review of this project, see Weimann, 1982, 1983). The communication matrix included 2,511 entries or communication ties, connecting the 270 members of this community. Using sociometric analysis of the $270 \times 270$ matrix, we computed the network position of each individual by the number of links that tie him to other members. This measure of network centrality was then compared to the PS ratings, applying the 10-item PS scale to the same kibbutz members. The two measures were highly correlated: A correlation coefficient of.54 was found between the individual's number of communication links (in the entire network) and the PS measure. This correlation was even higher when relating the PS score to the number of communication links within the individual's clique or group.

The successful identification of the influentials by means of the PS scale, validating the identification by 'external' criteria, and the relative ease of administrating the scale led more researchers to explore its potential. Noelle-Neumann (1999) has argued that the dispositional characteristic of personality strength might be of key interest in the study of political action and social capital. Personality strength is conceived to be a feature of individuals, a reflection of their confidence in leadership roles, their aptitude at shaping others' opinions, and their self-perceived impact on social and political outcomes. Such individuals, according to her data, show higher levels of life satisfaction and are more engaged in their communities (Scheufele, 1999). In an American study, Scheufele and Shah (2000) examined the relationship between strength of personality and social capital, using data collected as part of an annual mail survey conducted by Market Facts and funded by the DDB Needham advertising agency. They reported that 'results of structural equation modeling revealed that personality strength, an amalgam of self-confidence and opinion leadership, has a relatively strong direct impact on all dimensions of social capital, whereas informational variables have rather weak effects'.

The existence of numerous methods and their use in various societies, social settings and cultures and the variance across domains of opinion leadership raises questions on the applicability and validity of the modern, advanced methods in other societies. It should be noted that Noelle-Neumann's studies as well as Weimann's validation efforts were all conducted in modern, Western societies. How useful are these measures when applied to traditional, non-Western social settings? The present study applied all the methods, comparatively, in a South African community, Skukuza. 


\section{METHOD}

After discussions in Allensbach with the developers of the original PS scale, it was decided to conduct a validation study in South Africa, using a small and relatively isolated community in which most people knew each other. In addition, it was felt that not only should the questionnaire be used in the validation study, but also the more traditional methods of identifying opinion leaders in various spheres of life in the particular village. Moreover, it was suggested that literate people should be used, as well as a mixture of both black and white people in such a village.

The choice of a venue in South Africa fell on the staff village in Skukuza, the main rest camp of the Kruger National Park, situated in the north-eastern part of South Africa. The Kruger National Park is famous for its wild life and is a favorite tourist destination in South Africa. The staff village has more than 120 houses used by the personnel and their families. A school and church, recreational facilities such as an athletic track, tennis courts, and a full golf course are in the village. The village is not accessible to visitors to the Park, and is not seen from the roads to Skukuza due to the dense bush in the area. There is no fence around the village, and it is a common sight to encounter elephant, hyena, leopard as well as impala, kudu, and other game in the village.

The reasons for choosing the Skukuza staff village were:

- It was suggested at a meeting in Allensbach in March 2004 that an isolated community be used to test the validity of the PS scale, because of the inherent communication patterns found in these communities.

- The work done in Israel in a Kibbutz also suggested that an isolated community might provide a close social network where all individuals know each other or at least most of the community.

- Although the village is isolated, all houses have access to radio and television, and newspapers are sold at the local grocery shop; thus the community is exposed to mass media.

- The village reflects much of the transformation of the demographics in South Africa, in the sense that the majority of the inhabitants of the village are now blacks, whereas ten years previously, the village consisted mostly of white staff members.

- All of the inhabitants are literate, and would be able to complete the questionnaire.

The survey population included all residents of the Skukuza staff village. Most of the sample members were selected at random. Prior to random sampling, the influentials residing in the staff village were identified by means of judgmental procedures (nonprobability sampling). This involved the identification by the local church minister of 12 influentials in the Skukuza 
staff village. This approach also served to test the validity of the reputational approach in identifying influentials relative to the PS scale model. Apart from the identified influentials, 50 additional staff members of Skukuza were randomly (probability sampling) selected to participate in the research. This allowed individuals to be identified according to PS scale measurements. Although more than one influencer research model was tested for validity among the Skukuza residents, the core of the sample population consisted of 62 respondents $(n=62)$.

Data gathering in this community was rather difficult due to the fact that most of the community members were working during the day and only returned to their homes at evening. Furthermore, the proximity of dangerous animals at night made interviewing at home a risky procedure: we found ourselves on the way to interviews or back to our house in the village looking at hippos, elephants, hyenas, warthogs, and herds of impalas, all wandering among Skukuza's houses. Therefore, it was decided to conduct personal face-to-face interviews at various working sites (shops, restaurants, offices), and at homes in the village during the few hours before sunset. Owing to the difficulties encountered with personal face-to-face interviews, data collection was further supplemented with a self-administered approach. The fieldwork took place in August 2005. The entire sample was interviewed; thus the response rate was 100 percent. All the respondents were proficient in English; thus all interviews were conducted in English.

The PS items were included in the questionnaire with the aim of testing their validity within a South African context. In addition to the PS scale questions, further questions were included to identify people whose advice was sought in various decision-making circumstances. More specifically, the following questions were included:

- If you or a family member has health-related problems, who in your village will you consult?

- If you or a family member has financial problems, who in your village will you consult?

- If you or a family member considers buying an expensive item such as a car or washing machine, who in your village will you consult?

- If you or a family member wants to know more about HIV/AIDS, who in your village will you consult?

- Who do you consult regarding family planning?

The items measured in the model as reflected earlier mostly refer to very personal matters that people will rather discuss with family members. However, the outcome of the research findings shows that other sources such as medical practitioners and financial institutions were also consulted. By including these questions, the research model was designed to also 
construct and test the validity of sociometric modeling. The questionnaire also featured items related to self-designation as an opinion leader. Typical questions in this regard included: 'In your village, are you considered a source of advice?' Affirmative responses to this question were followed by questions to detect the areas of advice (e.g., shopping/marketing; money/finance/ investments; education; health/medicine/healing; technical advice; birth control/pregnancy; HIV/AIDS). Finally, the questionnaire included items on exposure to mass media and social gregariousness. These questions were added on the assumption that influentials show higher levels of engagement with mass media and socialize often with friends/colleagues.

\section{FINDINGS: THE FUTILITY OF THE PS SCALE}

The dual approach to identify the opinion leaders, namely the PS scale and the reputational method, was meant to compare their validity in a more traditional community. The PS scale did not work well for our South African community: From the first analysis of the data it became clear that this scale that proved to be efficient in Western, advanced societies (Germany, Israel, and the USA) yielded poor results in a traditional community like Skukuza. First, the respondents' results on the scale were highly skewed toward the higher score, resulting in a higher PS average than those found in Germany, the USA, and Israel. Moreover, the German and Israeli studies applied a split-half reliability test to the PS scores and found coefficients of .78 and .76 for the German and Israeli samples, respectively (Weimann, 1991, p. 271).

To provide some statistical analysis to validate the applicability of the PS scale model, a reliability analysis was conducted. The value of the reliability analysis is reflected by, among others, the fact that it provides information about the relationships (correlations) between individual scale items. This analysis presents interclass correlation coefficients used to compute reliability estimates. The outcome of the reliability analysis for the influentials group (as identified by the PS scale) was rather disappointing, especially for the PS scale measures: most of the inter-correlations were rather weak, reflecting weak relationships for most scale items.

A principal component factor analysis was used to test whether the scales are onedimensional, and to determine, by means of the Kaiser criteria, how many factors result from the items. All factors with an eigenvalue of more than one were considered relevant. When the 10-item PS scale was factor analyzed in the German and Israeli sample, two distinct factors emerged: a principle one accounting for 75 percent of the variance (German sample) and 72 percent (Israeli sample) that included seven items and a second factor that included the remaining three items. The two factors were easily explained since the first factor was related to items measuring internal sources of 
influencabililty while the second factor relates to items measuring external sources. However, a factor analysis applied to the PS scale in the Skukuza community yielded poor results: five factors emerged and account for 73.9 percent of the variance if combined. Another test was to add 10 'filler items'. When a similar procedure was applied in the German and Israeli studies, the 10 items of the PS scale emerged as strongly loaded on one factor, accounting for about 41 percent of the variance. In the Skukuza case, a factor analysis of all the 20 items (including the 10 PS scale items) did not provide a factor with the PS scale items but a factor that involved both PS items and other non-PS items (explaining 39 percent of the variance).

But the most devastating results for the PS scale was its impotence in terms of predicting influence, communicative patterns, flow of information or influence, media consumption, etc. All the studies that applied the PS scale in Western societies found evidence of this scale's potential to predict a person's communicative position in social networks, activation of social ties for the flow of communication, being influential, and serving as a source of advice and guidance for others. If indeed the PS scale identifies the influentials then we would expect respondents with high PS scores to serve as sources of advice and guidance, to hold a prominent communication status and to show heavy media consumption. However, none of these patterns were revealed in the Skukuza study: the PS scale results were not related to any evidence of communicative status. Let us demonstrate the futility of the PS scale with some illustrative analyses.

As performed in all PS studies, the respondents were divided into four groups according to the quartile scores on the PS scale. The upper quartile, the 'influentials' according to the PS studies, was examined in terms of its communicative effectiveness when compared to the others. Thirteen individuals ranked as high PS but we could not find any unique communicative advantage or status related to them. For example, nine people in this community were listed by several respondents as their source of advice and guidance in various domains. There was no match between a high PS score and being designated by others as opinion leader $\left(X^{2}=142, d f=1\right.$, NS). Unlike other studies, in the Skukuza study high PS individuals were not showing any selfawareness of being influentials: there was no match between high PS and a positive answer to the question 'In your village, are you considered as a source of advice?' Among the high PS, 54 percent answered positively, compared with 61 percent among the other PS levels $\left(X^{2}=1.76, d f=1\right.$, NS). Unlike all studies on opinion leadership, the high PS in Skukuza did not differ from others in media consumption, as shown in Table 2.

Another common feature of influentials is their social gregariousness. Most studies of opinion leaders found them very involved in social activities, socializing often with others, active in social events (Weimann, 1994). The use 
TABLE 2 Media consumption and PS

Among high PS Among others t-value

Average hours per day watching TV

2.78

3.69

.982 NS

Average hours per day listening to radio

3.09

2.57

$.778 \quad$ NS

*Testing the differences of the proportions under the null hypothesis of no significant difference (NS denotes 'not significant').

TABLE 3 Social activity and PS

\begin{tabular}{lcccc}
\hline & Among high PS & Among others & \multicolumn{1}{c}{$t$-value $e^{a}$} & \\
\hline $\begin{array}{l}\text { How often do you socialize with } \\
\text { friends outside work? How often }\end{array}$ & 3.23 & 2.73 & 1.63 & NS \\
$\begin{array}{l}\text { do you socialize with } \\
\text { your colleagues at work? }\end{array}$ & 2.31 & & 1.56 & NS \\
\hline
\end{tabular}

*Testing the differences under the null hypothesis of no significant difference (NS denotes not significant). Scales range from 1 ('not at all') to 5 ('very often').

of the PS scale in American, German, and Israeli samples found strong relationships between measures of gregariousness and high PS scores. However, this pattern was not found in Skukuza, as shown in Table 3.

When we examined the sociometric mapping of the community based on asking the respondents to name the people they talk to about different issues (in eight domains, from shopping to educating children) and people they ask for advice or guidance, we could not trace any structural advantage of those with high PS scores. They were not 'centrals,' they did not see themselves as 'centrals,' they were not rated as more active communicators and they were not sought after by others for advice or guidance.

Although we focused on the usability of the PS scale, our data gathering relied also on using the reputational method, self-designation and a sociometric approach. The futility of the PS scale was even clearer when contrasted with other, more traditional and conservative measures. First, we looked at the self-designation and the sociometric mapping of the flow of advice and guidance in eight different domains. There were nine individuals who were mentioned by several others (three or more) as their source of advice. We examined the match between this sociometric designation with self-designation (based on the question 'In your village, are you considered as a source of advice?'). Unlike the case with PS scale, where no match was found, it was clear that the self-designation and designation by others were correlated. The match between the two measures is significant $\left\{X^{2}=5.27, d f=1, p<.03, \boldsymbol{\phi}=.30, p<.02\right.$ ) and clear: In fact all but one of the 
self-designated influentials were identified as influentials by others. Thus, those individuals who saw themselves as influentials were also seen as such by their community members (with the two measures being totally independent). Moreover, the attributes that usually relate to opinion leadership were correlated with the traditional measures. For example, those who were identified by the sociometric method as influentials tended to be more exposed to mass media (television and radio), to be more involved in social activities, to socialize more with others at work or outside work.

The use of a key informant was found to be much more valid in identifying the sources of influence than the use of the PS scale. We compared the $\mathbf{1 3}$ 'reputational leaders' with nonleaders and the 'PS leaders' with nonleaders in terms of serving as source of advice (in general and broken down by domain) and the results are presented in Table 4.

It is clear that while the leaders identified by the key informants were indeed more active as sources of advice and in all domains, the PS leaders were not significantly more active than nonleaders in most of the domains. The reputational method certainly worked much better than the PS method for the identification of those individuals in the Skukuza community who were active influentials. In short, the PS scale did not identify the influentials, did not correlate with traits associated with opinion leadership and did not yield the reliability results that were found in other studies using the same scale. In contrast, the use of 'traditional' measures proved to be more fruitful.

\section{CONCLUSION}

The present study is in fact a first attempt to apply the modern PS scale to a traditional community. In earlier research, the PS scale had been found to be an efficient, valid, and useful instrument to identify opinion leaders. However, it was always used, tested, and validated in Western societies (e.g., Germany, USA, and Israel). When we applied the method the Skukuza community, a small village in South Africa, the findings revealed the inapplicability of the scale in a traditional community. Several factors may explain the futility of the PS scale in traditional society when compared to either the success of the PS scale in modern societies or to the effectiveness of traditional methods when used in a traditional community like Skukuza.

The first has to do with the development and refining of the PS scale, which was all done within a specific socio-cultural setting. As our pivotal attempt reveals, the relevance and applicability of the influentials concept and its operationalization in other social settings is to be determined. Our findings may indicate that modern scales such as the PS scale are applicable in modern societies while the traditional methods (sociometric mapping, informants' reports) are more efficient in traditional communities. Let us illustrate this 
TABLE 4 Serving as source of advice

\begin{tabular}{|c|c|c|c|c|c|c|}
\hline & \multicolumn{3}{|c|}{ Personality strength } & \multicolumn{3}{|c|}{ Reputation } \\
\hline & $\begin{array}{c}\text { Leaders } \\
(n=13,)(\%)\end{array}$ & $\begin{array}{l}\text { Nonleaders } \\
(n=49)(\%)\end{array}$ & $\mathrm{p}^{\mathrm{a}}$ & $\begin{array}{l}\text { Leaders } \\
(n=13,)(\%)\end{array}$ & $\begin{array}{l}\text { Nonleaders } \\
(n=49)(\%)\end{array}$ & $\mathrm{p}^{\mathrm{a}}$ \\
\hline$\overline{\text { In general }}$ & $75-0$ & 62.9 & $<-05$ & 91.7 & 56.0 & $<<.00 \mathrm{I}$ \\
\hline Shopping/marketing & 18.8 & 21.3 & NS & 50.0 & $13 \mid 7$ & $<.00 \mathrm{I}$ \\
\hline Money/finance/investment & 31.3 & 23.4 & NS & 50.0 & 196 & $<.00 \mathrm{I}$ \\
\hline Education & 50.0 & 36.2 & $<.0_{5}$ & 50.0 & 373 & $<.0 \mathrm{I}$ \\
\hline Health/medicine/healing & 25.0 & 17.0 & NS & 58.3 & \begin{tabular}{l|l}
9 & 8
\end{tabular} & $<.00 \mathrm{I}$ \\
\hline Technical & 31.3 & 8.5 & $<.0_{5}$ & $33-3$ & $8 \mid 5$ & $<.00 \mathrm{I}$ \\
\hline Birth control/pregnancy & 12.5 & 10.8 & NS & 41.7 & 39 & $<.00 \mathrm{I}$ \\
\hline HIV/AIDS & 18.8 & 14.9 & NS & 58.3 & 3-9 & $<.00 \mathrm{I}$ \\
\hline
\end{tabular}

${ }^{\mathrm{a}}$ Testing the differences of the proportions under the null hypothesis of no significant difference (NS denotes 'not significant').

See text for question wording and definition of leaders and nonleaders. Due to missing data, some percentages are based on lower $\mathrm{n}$ than indicated. 
cross-social differentiation by one example: after applying the PS scale to the first respondents in Skukuza, it became clear to us that the issue of 'social desirability' was affecting our results. The PS items caused some uneasiness among the respondents and many of them were consistently choosing the seemingly 'desirable' answer, causing the distribution of the PS scale results to be skewed upwards. This was not observed in Western samples.

The second set of factors has to do with the specific attributes of the Skukuza community. This is a mixed community of white and black residents, a community that undergoes a process of transformation, and a community that survived several traumatic events (devastating floods in 2000 and large-scale retrenchment of middle management in 2001-2002). The multi-racial and multi-ethnic nature affects the patterns of communication between subcommunities, each with a sense of identity and boundaries (the 'ins' and the 'outs'), and with special vocabularies, idioms, in-group jokes, and specified patterns of communicating with insiders and outsiders. For a group to work together in a situation of social change requires openness of communication among members and among internal subgroups. If communication breaks down, cooperation disappears quickly, motivation evaporates, efforts become fragmented, and antagonisms accumulate.

These factors may all work together to affect the applicability of the PS scale. Our failed attempt to apply it in a traditional community should encourage future research to study and redefine the scale's universality across societies, cultures, and social settings. An adapted PS scale model might become more effective even in Skukuza should the social dynamics stabilize over time. From a research point of view, it appears that utilizing the reputational model to identify influentials is fairly successful and should be built upon in future research. Our findings support an emerging hypothesis that identifying opinion leadership by traditional measures based on observations, sociometric mapping, and key informants' reports are more useful in developing societies.

\section{REFERENCES}

Brosius, H.-B., \& Weimann, G. (1996). Who sets the agenda? Agenda setting as a two-step flow. Communication Research, 23, 561-580.

Katz, E. (1957). The two-step flow of communication: An up-to-date report on an hypothesis. Public Opinion Quarterly, 21, 61-78.

Katz, E., \& Lazarsfeld, P. F. (1955). Personal influence. The part played by people in the flow of mass communication. Glencoe, IL: Free Press.

King, C. W., \& Summers, J. O. (1970). Overlap of opinion leadership across consumer product categories. Journal of Marketing Research, 7, 43-50.

Lazarsfeld, P. F., Berelson, B. R., \& Gaudet, H. (1948). The people's choice: How the voter makes up his mind in a presidential campaign. New York: Duell, Sloan \& Pierce. 
Menzel, H. (1981). Interpersonal and unplanned communications: Indispensable or obsolete? In E. B. Roberts, R. I. Levy, S. N. Finkelstein, J. Moskowitz \& E. J. Sondik (Eds.), Biomedical Innovation (pp. 155-163). Cambridge, MA: MIT Press.

Merton, R. K. (1949). Patterns of influence. In P. F. Lazarsfeld \& F. N. Stanton (Eds.), Communication Research, 1948-1949 (pp. 180-219). New York.

Noelle-Neumann, E. (1983). Spiegel Dokumentation: Personlichkeitsstarke. Hamburg: Spiegel Verlag.

Noelle-Neumann, E. (1985, September). Identifying opinion leaders. Paper presented at the 38th ESOMAR Conference, Wiesbaden.

Noelle-Neumann, E. (1999, January 13). Ein Museum der Irrtiimer: Die Ergebnisse der empirischen Sozialforschung finden keinen Eingang in die Gesellschaft [A museum of errors: Results of empirical research do not make their way into public discourse]. Frankfurter Allgemeine Zeitung, p. 5.

Rogers, E. M. (1983). Diffusion of innovations (3rd ed.). New York: Free Press.

Scheufele, D. A. (1999). Participation as individual choice: Comparing motivational and informational variables and their relevance for participatory behavior. Unpublished doctoral dissertation. University of Wisconsin, Madison.

Scheufele, D. A., \& Shah, D. V. (2000). Personality strength and social capital. Communication Research, 27, 107-131.

Solomon, M. R. (1994). Consumer behavior (2nd ed.). Boston: Allyn and Bacon.

Solomon, M. R. (1999). Consumer behavior: Buying, having, and being (4th ed.). Upper Saddle River, NJ: Prentice Hall.

Weimann, G. (1982). On the importance of marginality: One more step into the two-step flow of communication. American Sociological Review, 47, 764-773.

Weimann, G. (1983). On the strength of weak conversational ties. Social Networks, 5 , 245-267.

Weimann, G (1991). The influentials: Back to the concept of opinion leaders? Public Opinion Quarterly, 55, 267-279.

Weimann, G. (1994). The influentials. People who influence people. Albany: State University of New York Press.

Weimann, G, \& Brosius, H.-B. (1994). Is there a two-step flow of agenda setting? International Journal of Public Opinion Research, 6, 323-341.

\section{BIOGRAPHICAL NOTES}

Prof Gabriel Weimann is a Full Professor of Communication at the Department of Communication, University of Haifa, Israel. His research areas are media effects, political communication, terrorism and the media and social networks. He published six books and over 120 scientific articles.

Prof. Deon H. Tustin is currently heading the Bureau of Market Research at the University of South Africa (Unisa) and specializes in behavioral and communication and socioeconomic research.

Dr Daan van Vuuren is a Research Fellow at the Bureau of Market Research at the University of South Africa. He is also an Extraordinary Professor in the Department 
of Psychology at the University of Pretoria. He consults in the marketing research industry as a Research Psychologist.

Prof. Pierre Joubert is the incumbent of the Clover Chair in Consumer Psychology in the Department of Industrial and Organizational Psychology at the University of South Africa (Unisa).

Address correspondence to Gabriel Weimann, University of Haifa, Department of Communication, Mount Carmel, Haifa 31905, Israel, E-mail: Weimann@soc.haifa.ac.il 